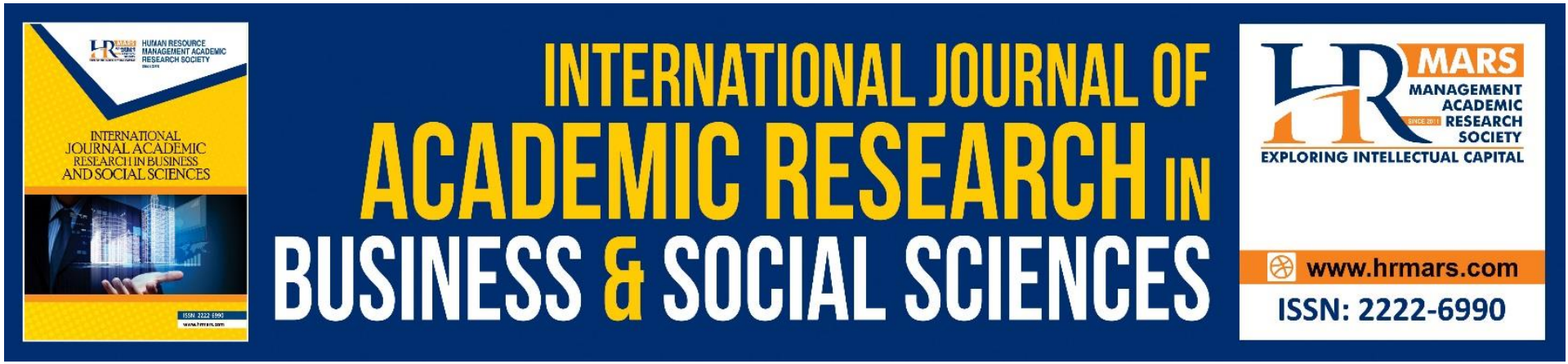

\title{
An Initial Attempt: A Synthesis of Cultural Adaptation and Representation in Animation
}

\section{Muhamad Azhar Abdullah, Nabilah Abdullah}

To Link this Article: http://dx.doi.org/10.6007/IJARBSS/v10-i12/8354

DOI:10.6007/IJARBSS/v10-i12/8354

Received: 07 October 2020, Revised: 12 November 2020, Accepted: 30 November 2020

Published Online: 26 December 2020

In-Text Citation: (Abdullah \& Abdullah, 2020)

To Cite this Article: Abdullah, M. A., \& Abdullah, N. (2020). An Initial Attempt: A Synthesis of Cultural Adaptation and Representation in Animation. International Journal of Academic Research in Business and Social Sciences. 10(12), 546-557.

\section{Copyright: @ 2020 The Author(s)}

Published by Human Resource Management Academic Research Society (www.hrmars.com)

This article is published under the Creative Commons Attribution (CC BY 4.0) license. Anyone may reproduce, distribute, translate and create derivative works of this article (for both commercial and non-commercial purposes), subject to full attribution to the original publication and authors. The full terms of this license may be seen at: http://creativecommons.org/licences/by/4.0/legalcode

\section{Vol. 10, No. 12, 2020, Pg. 546 - 557}

Full Terms \& Conditions of access and use can be found at http://hrmars.com/index.php/pages/detail/publication-ethics 


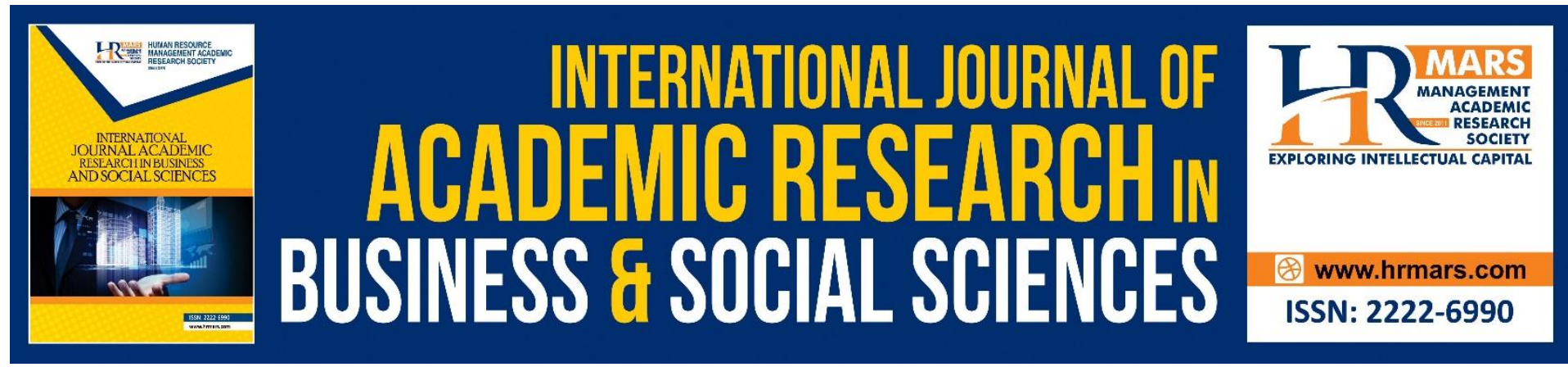

\title{
An Initial Attempt: A Synthesis of Cultural Adaptation and Representation in Animation
}

\author{
Muhamad Azhar Abdullah \\ Faculty of Film, Theatre and Animation, Universiti Teknologi Mara (uitm), Selangor \\ Branch, Puncak Perdana Campus, 40150 Shah Alam, Selangor \\ Email: azhar624@uitm.edu.my
}

Nabilah Abdullah

Fakulti Pendidikan, Aras 5 \& 7, Bangunan fsk 1, 5, Kampus Puncak Alam, 42300 Bandar

Puncak Alam, Selangor Darul Ehsan, Malaysiaa

Email:nabil789@uitm.edu.my

\begin{abstract}
The use of cultural representation is becoming more evident in contemporary animation and has developed its own circle of aficionados. The intensification of criticisms on the use of cultural elements in contemporary animation is most apparent after the release of the feature-length motion animation - Mulan, in 1998. It has been set as an exemplification of an erroneous attempt for cultural adaptation in an animation. However, Nikelodeon's animated series Avatar: The Last Airbender (2005-2008) succeeded its predecessor, Mulan, from critical criticisms and controversies related to cultural adaptation despite displaying distinct visual cultural elements which were immersed in its animated features. This paper delved into reviewing the exploits of cultural representations that are integrated in the arts and storytelling of an animation production and attempts to synthesise the findings comprehensively. The synthesis reveals that although the elements used in an animation may have distinct visual cultural elements, the adapted intricacies and 'shifts' in animated visuals and storytelling have trawled meaningful transcultural audiences.
\end{abstract}

Keywords: Cultural Representation, Contemporary Animation, Transcultural Audience, Cultural Shift

\section{Introduction}

Cultural appeal has been exploited in animation either for short or full-length animated productions, television series and video games since its early developmental years such as Lotte Reiniger's 1926 full-length silhouette animation titled The Adventures of Prince Achmed. The practice of injecting cultural elements for audience appeal in many contemporary animation productions, especially since the release of Disney's animated feature-length Mulan in 1998, has received numerous criticisms for various reasons including fallacious cultural representations. Those who made their observations with relative inclinations in historical or socio-anthropological perspectives might find that inaccurate representations on 
the details and elements of certain people and cultures are presumptuously ignorant. Therefore, it is critical to apprehend that the use of animation in presenting a story based on either an adoption or adaptation of non-fictional events is a form of utilizing an instrument to "offer a different representation of reality or create worlds governed by their own codes and convention that radically differ from the real world," (Wells, 2006, p.10).

The animated series Avatar: The Last Airbender produced by Nikelodeon which aired from 2005 and ended in 2008 is a substantiation of the proposition made by Wells. The series have chiselled notable character design and background setting that are visually and culturally marked as Asian but not exclusively ascribing to a culture or people in its entirety. Though the characters and background used in the animated series are not ascribed to any specific Asian identity, blending mimesis and fantasy in the animation arts have garnered Avatar: The Last Airbender global acclamation. The subsequent paragraphs provide a review on the animated series' successful presentation of distinct East Asian identity through its character design and background setting, while stroking elements of culture with finesse that deserves a venerable installation in the study of animation. Therefore, it is valuable to further investigate the uses of heritage elements in animation towards a more sustainable creative-cultural development and in efforts to avoid contentious observations from the audiences.

\section{Background of the Study and Rationale}

Culture has a crucial role in the sustainability of a people and nation which eventually is considered as one of UNESCO's seventeen Sustainability Development Goals. Within the framework of the SDGs, culture has been given its due attention in UNESCO's efforts towards cultural inclusivity in the socio-economic development of a nation. With leading-edge development being exploited in numerous activities, the SDGs work in tandem with the aspirations of experts and organizations in various sectors towards developing a sustainable culture. Believing that efforts can be optimized through collaborations and partnerships with the creative industries, UNESCO's SDG can be used as a framework that promotes "culture as the enabler and driver towards economic, social, and environmental dimensions of sustainable development" (UNESCO). Therefore, the animation industry can benefit from such efforts in promoting heritage to the audiences through cultural representations in animation.

Many sectors are becoming more aware on cultural diversity especially with the development of cutting-edge technologies where information are easily made accessible. Animation is among the trailblazing sectors that move progressively in its innovation alongside technological advancement. Although animation has for many years integrated cultural elements in its presentation, it did not get much global attention in the more contemporary setting until the release of the full-length motion animated Mulan in 1998. Many criticisms arise when critiques highlighted what are believed to be evident cultural misrepresentations. It was later cautioned by Wells and Moore (2016) that the creative fantasies by animation creators can be considerably in contrast to the real world setting. They further highlighted the importance of performing detailed research during the pre-production stage in the development of an animation production. Since animation is a presentation that involves the dynamics of visual arts and sequential visual storytelling, the audiences are able to inspect almost every aspects of a production. The debates built up concerns in diverse topics with regard to cultural representations in animation and this include identifying the justification for using cultural content in an animation production. 
It may also need to be underlined that animation as a form of adaptation entails for some form of re-writing in the source of the material. Consequently, if cultural elements are to be exploited in an animation production, it might be best to have a framework that can provide some form of direction in the selection of cultural elements to be appropriately used in an animation towards developing adequate visual and audio-visual representations. Systematic observations on the cultural poly-system could increase further awareness of the acceptable and non-acceptable elements to be used even with some touches of adaptations. Nevertheless, it may be applicable to use the recommended suggestions by Perdikaki (2018) in the context of animation that adapting content from a literature (in this context, culture), would involve rewriting in that source of material but 'repackaged and repurposed for a new audience' (p. 172). Perdikaki went on to suggest that adaptations would still rely 'on the norms and conventions in the systems involved' (p. 172) and in this case, animation production process.

With good technologies and avant-garde tools becoming more accessible, innovation in animation becomes remarkably vigorous. Numerous productions have experimented and optimized these augmented technologies to produce animation for increased transnational and transcultural audiences. It needs to be cautioned though that, aside from criticisms on the arts of the animation, critics may expatiate constant denigration on the aspects of cultural accuracy. While animation allows for the invention of all things beyond reality, Wells and Moore (2016) had asserted that although the animator can be imaginative as possible, it is essential 'to know how that which is imagined can be realised'. This is because, representations created through the animation can have a different 'reading' of the cultural product through the animated process.

\section{Adaptations in Animation}

Culture is a median that connects people or groups of people. Hall (1997) suggested that culture carries speckled of meanings on various matters through the representations of diverse languages, signs, images, and ways of doing things within a group of people or groups of people. He further emphasised that culture involves 'feelings, attachments, emotions, concepts and ideas'. For centuries, cultural elements have also been passed down through stories from generations to generations in various formats that include oral narration, the use of symbols, visual images, and textual documentation. As centuries passed, many of these stories went through changes and adjustments in adapting through time and environment. Hence, adaptations are often used as a means of showcasing cultural representation in visual narrative.

While storytellers and creators would refine and render their narratives through rigorous selections, some may be found to have similarities in the transcultural setting. For instance, the fairy-tale Cinderella in the Western culture and the folk-story of Bawang Merah Bawang Puteh in the Eastern culture have several versions of adaptations either in television series, movies, or animations. Though their origins are geographically and culturally distant, these two narratives tell the story of an orphan girl who was mistreated by a step mother and step sisters (however, the latter only had one step-sister). Cinderella and Bawang Puteh both get the assistance of enchanted creatures in going through their ordeals, and ultimately went through all odds to finally be married to their prince charming. The stories like Cinderella and Bawang Merah Bawang Puteh can be universally found but they come with distinct cultural fragments that depend on the geographic origin of the story. Although adaptations may be produced in different settings and formats, it is a form of repetition but without replication. 
Adaptation may not involve inventing anew but it is an overt action that ascribed to its original source (or sources) as demonstrated in Avatar: The Last Airbender. However, the multiple processes of animation needs to be considered in creating a successful animation that is based on cultural adaptation.

Adaptation is a process of creation that involves re-interpretation and re-creation from a 'real life source' that is a complex representation of reality (Hutcheon, 2006). It needs to be emphasized that an animation production is an 'artwork' that involves many artists (or production team). Unlike other forms of visual arts such as photography, painting, or sculpting, which are usually an individual effort, animation involves various team members in its production. The creative decision of one person in the production team would affect the complex process involving others (Agnoli, 2020). As was mentioned by Lioi (2009, p. 2) communication is imperative along with shared experiences and the understanding of design processes. This is further implied by Agnoli (2020) that animation is the process of creating and combining various components into a fluid and unified presentation. It could be observed that Mulan may have experienced some misrepresentations and mis-recreation when many of its criticisms highlighted on its failure to keep the fidelity from the original cultural source that it attempted to exclusively depict. One of the most highlighted recurring criticism the feature-length 1998 animated Mulan received was how the creators had 'Americanised' the story and its character design as a whole (Langfitt, 1999). The Disney's Mulan had failed in its appeal especially to the Chinese audiences claiming that the creators failed in their understanding of the Chinese folktale and culture. For this reason, researching in the cultural context requires conscious cautions and should not be rushed.

Researching is extremely important in adaptation which include acclimatising from cultural content because creators may find some transcultural similarities in the stories such as that of Cinderella in the West and Bawang Merah Bawang Putih in the Malay Archipelago. It needs to be emphasized here that though the stories may have some common characteristics, these do not mean that the stories are identical due to their geographic and ethnographic specifics. For this reason, animated adaptation from an original source especially when the source is not native to the creators may experience 'collision of esoteric competence' which happened to the 1998 animated feature-length Mulan. When practitioners display 'unique, uncertain, and conflicted situation of practice' (Balodis, 2012, p. 3; Mughal, 2019) this would require flexibility and fluidity in the poly-system of animation. Reviewing the work of William Froug (2000), Balodis further asserted that creators need to make clear distinction between 'the craft' and 'the art' of storytelling. It was contended that 'the craft' of storytelling which include shaping of plot, character, and script are skills that can be taught in specific time. However, to study 'the art' of storytelling would take years of conscientious process. Baladis simply put it "that mastering the art is a continuous and life-long project of reflective practice" $(2012$, p. 3). Eventually, years of technological advancement have further influenced the practices and processes in animation.

The advancement of technologies have allowed for adaptations of 'real world' elements to be exploited in animation production with enthralling or beyond reality details. This include in the exploits of cultural elements in the arts of animation through adaptation. The use of cultural elements in the production of animation is not a new-fangled approach. Cinema history has demonstrated a long thread of adaptations which Giannalberto Bendazzi had asserted in an interview with Rall (2020) that it is only likely for it to ensue in animation. Bendazzi further asserted that the first European animated feature film was an adaptation from the 1001 Arabian Nights collection of stories that has traces of various geographical and 
cultural origins. The animated feature film was The Adventures of Prince Achmed produced in 1926 Germany by Lotte Reiniger. Of course, much has changed since the silhouette animation era as animation technology advances into the $21^{\text {st }}$ century. Nevertheless, awareness on cultural diversity is becoming recognized globally with the advancement of digital media. Cutting edge technologies have allowed for massive information sharing and the use of social media platforms further accelerate transmission of information. Hence, the propensity for technologies to spark controversies is expected. This include in the arts of an animated production.

\section{Cultural Representation in Animation}

It was explained by Giannalberto Bendazzi (Rall, 2020) that adaptation is a form of repeated storytelling but with variation from one culture to another through revitalized methods. It was further asserted that although an original source is being referred to, animation allows its creators to invent anything at all even those beyond reality. Hence, debates and controversies ensue. When certain cultural elements are used in an animation that allows for creators to reinvent and re-create a figment from what is real, it may send false impression of a culture and disparaging to its values. However, Agnoli (2019) described that "in the context of globalization, artefacts, ideas, and personnel crossed or were brought across borders" thus putting the creative process of animation in the transculturation spot.

The fidelity or authenticity of arts in animation to the multiple real-world inspirations (i.e., cultural representation) may not be distinctly accurate thus, impacting the transcultural nature of animation. Agnoli (2019) went on to suggest that through creative decisions, animation creators would mediate their ideas through mimesis and fantasy. Consequently, this would affect the visual representation of culture used in the animation which conceivably tied to techniques and system in the field. This may be referred to Agnoli's suggestion that the inspirations from the real-world are only referents towards creating the 'fantastical cultural signifiers' for believable storytelling. Therefore, it is acceptable to agree with Perdikaki (2018) that the process of adaptation fundamentally involves rewriting from the original materials or sources which are 'repackaged and repurposed for a new audience' ( $p$. 172). Essentially, it was also emphasized that the process is integrated to 'the norms and conventions in the systems involved' and in this particular case, animation. It may be safe to say that, using cultural representations in animation may not reflect or reproduce the authentic real-world inspirations; instead, it is reinterpretation through creative processes for new circumstances.

The 1998 animated Mulan which was meant to trawl for transcultural and transnational audiences has invoked much debate on cultural representation through adaptations in animation. Although adaptation of cultural elements have been used since the beginning of animation history, Mulan had prompted for more global awareness that followed with multiple criticisms on the use of cultural representation or misrepresentation in animation. The criticisms on Disney's effort of demonstrating cultural representation include the creative changes it made in its juxtaposition of telling stories from other cultures (Anjirbag, 2018). The creative transformation accorded from the culture source may be purposefully decontextualized and reframed for more 'universal' acceptance to the audiences to which Anjirbag refer as the Western audience. Hence, cultural representation through adaptation in animation is essentially connected to sociocultural context where the animation is produced and presented aside from perhaps being commercially-motivated, and creativelyinspired (Perdikaki, 2018). However, it may cause for the cultural source to be lost in 
translation especially when it is being told from a 'foreigner's perspective'. Consequently, it lead to the collision between fidelity and artistic interpretation where cultural point of views would also contrast.

It has been emphasized by Hutcheon (2006) that "neither the product nor the process of adaptation exists in a vacuum: they all have a context-a time and a place, a society and a culture," (xvi). Adapting from the cultural source is what Hutcheon asserted as a palimpsest of cultural layers and a simplistic adaptation effort could seriously cause cultural misrepresentation. Nickelodeon's Avatar: The Last Airbender had demonstrated cultural finesse through its rendition of cultural adaptation in an animation. As revealed by Agnoli (2019), the creators had successfully selected visual elements in their attempt 'to preserve, erase, or alter' and had tactfully compounded 'mimesis, fantasy, and abstraction' in the animated production. They had diplomatically presented a palimpsest of 'cultural change' in a high fantasy visual presentation for transcultural audiences.

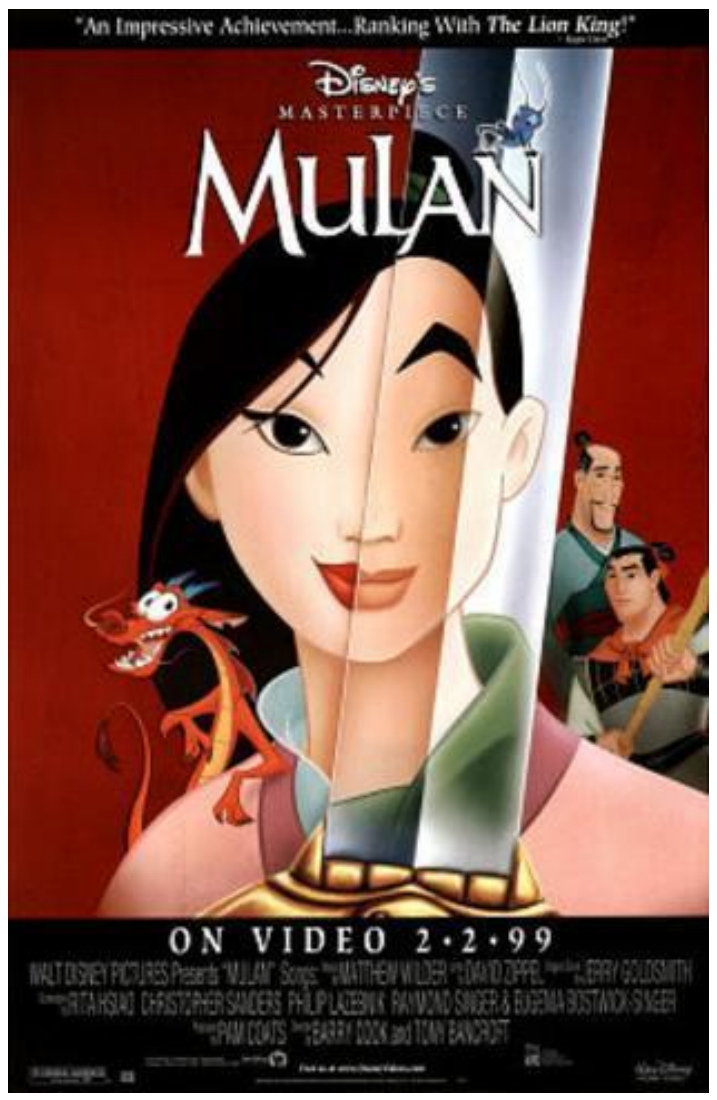

Figure 1: Mulan animated feature length 1998 (AllPosters, n.d.)

Authentic Cultural Representation and Otherness in Animation

Although the use of cultural elements have been prevalent since early history of animation, efforts to illustrate cultural diversity and appreciation of cultures in animation are more apparent since the release of Mulan in 1998. Various criticisms ensued and censures on the representation of cultural elements through adaptations include authenticity, misrepresentation, and the otherness presented in the contemporary audio-visual production. Nevertheless, Perdikaki (2018) averred that adaptation and translation from the real-world sources (i.e., cultural elements) should not understate creativity. This is clearly 
demonstrated in Nikelodeon's animated series Avatar: The Last Airbender (2005-2008) which had successfully exploited mixed cultural and ethnographic methods.

Adaptation in the transcultural milieu involves a change of language, different context, and time. Hence, the unadulterated authenticity of the cultural elements used would have an accompanying shift which Hutcheon (2006) termed as 'transculturated'. It was also reminded that time and context would influence cultural changes but that do not guarantee adapters (i.e. animation creators) would keep their fidelity of the sources they refer to. This is because various considerations within the practice would be involved in the entirety of an animated production process. Hence, to any observers of cultures, the creative and artistic shifts in the cultural elements for an adaptation are misrepresentations of the cultural source. Although it is known that Mulan is not a fairy tale, a term that is common to the literary Western culture, the story of Mulan was generally termed as a 'Disney fairy tale' under the company's umbrella after being incorporated with the corporation's 'transculturated' process. Subsequently, such shift raises the issue of misrepresentation to not only the narrative but also the character.

The visual in animation is organized frame-by-frame because movements are created rather than being recorded like life actions. McLaren as cited by Agnoli (2020) contended that: "Animation is therefore the art of manipulating the invisible interstices that lie between the frames." Hence, some of the missing motion may be created or recreated through artistic process. Although distinct cultural elements may be used in an animated production, it needs to be cautioned though that artistic mimesis is relatively incapacitated to precisely transmit the rudiments in reality. Consequently, the product may be accused of misrepresenting the authenticity of the cultural element. Animation creators may argue that adaptation is the reproduction of reality in abstraction to which the purity of reality or live action is reduced (Agnoli, 2020). This leads to the trepidation of the animated elements being different in appearance or character from what is familiar and generally accepted in the culture they attempt to depict. 


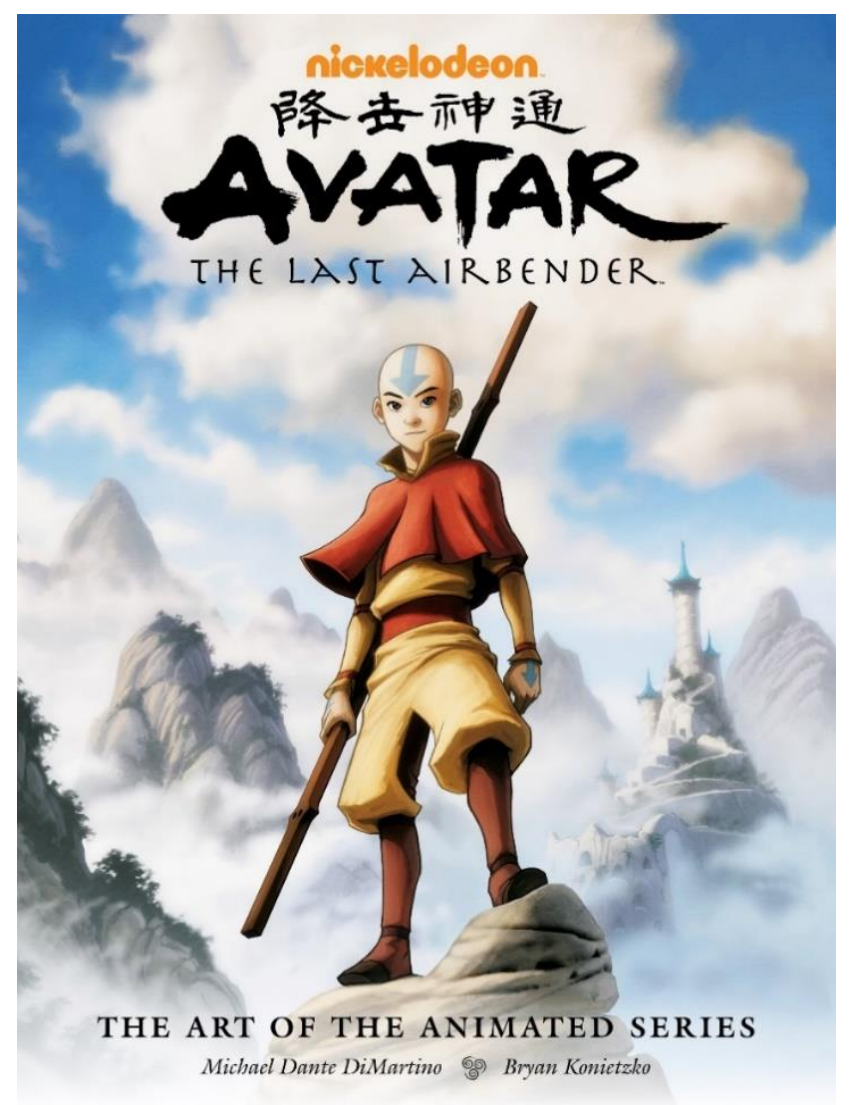

Figure 2: The book cover for Avatar: The Last Airbender - The Art of the Animated Series (DiMartino \& Komietzko, 2010).

The creative process of an adaptation has been known for making its creative shifts if necessary from its sources. That it has the predisposition to construct stereotypes as substitutes for reality. This is one of the causes that raised much criticisms in Mulan 1998 which further carried on till the present years. The visual depiction of reality in animated adaptation with regard to authentic cultural details may differ and affects the construction of fidelity to cultural identity. The issue of otherness in visualisation further create fraught of reproach among culture observers. However, Nickelodeon's Avatar: The Last Airbender does not face such critical denigration like Mulan despite being known to have depiction of transcultural elements in its overall content and visual arts. The animated series is the epitome of an animation that is full of fantasy but stands for what is reality to which Agnoli (2020) refer to as "the reduction of reality to its purest form". It was further accorded that by eliminating any superfluous elements, the illustrated facial appearance would gradually have that universal character which is more acceptable. 


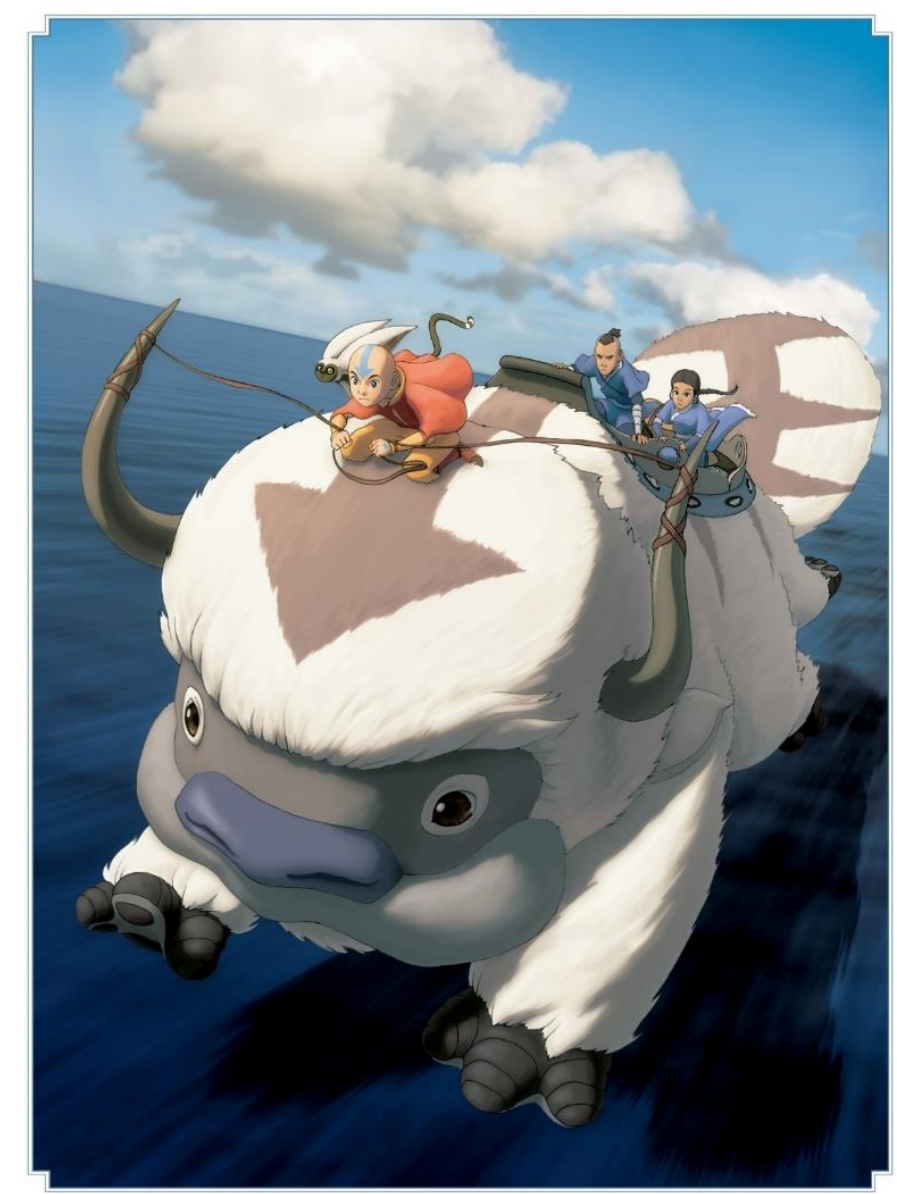

Figure 3: The art from the animated series Avatar: The Last Airbender (DiMartino, \& Konietzko, 2010).

\section{Conclusion}

The work of adaptation has some asymmetrical relationship between process and practices. However, the act of mimesis, reproduction and abstraction of reality still require some forms of progressive efforts towards creating the acceptable cultural adaptation, representation, and otherness. The pursuit of cultural authenticity for adaptation in animation requires a 'surgical treatment' that may improve cultural misrepresentation that may have significant 'Westernization' effects. Nevertheless, this synthesis has also highlighted that adaptation from an original source may be influenced by context and time that the adaptation was made. Not only that, the creative process of producing an animation involves many people and strings of procedures that affect fidelity to the 'authentic source'. Hence, future study may delve into identifying critical elements that can be the guiding fundamental framework towards an agreeable product of adaption for animation and perhaps in an effort to create 'cultural multiplicity' that is acceptable. This may be of novel importance especially when a transcultural study is performed for animation in South East Asia that has some similarities across nations.

\section{References}

Agnoli, F. M. (2019). Building the transcultural fantasy world of Avatar. Animation Studies (Special Issue: Transnational Animation). https://journal.animationstudies.org/francism-agnoli-building-the-transcultural-fantasy-world-of-avatar/ 
Agnoli, F. M. (2020). Animating race: The production and ascription of Asian-ness in the Animation of Avatar: The last Airbender and The legend of Korra. [Doctoral dissertation, University of East Anglia].

AllPosters (n.d.). Retrieved from https://www.allposters.com/-sp/Mulan-Movie-GroupOriginal-Poster-Print-Posters_i8758081_.htm

Anjirbag, M. A. (2018). Mulan and Moana: Embedded coloniality and the search for authenticity in Disney animated film. Social Science, 7 (11). https://doi.org/10.3390/socsci7110230

Balodis, J. (2012). The practice of adaptation: Turning fact and fiction into theatre [PhD]. https://eprints.qut.edu.au/60917/

DiMartino, M., \& Konietzko, B. (2010). Avatar: The last airbender - The art of the animated series. OR: Dark Horse Books.

Galvao, A. (2018). Using 'Avatar: The Last Airbender' to Explain Why Cultural Appropriation is Wrong, but Morally Permissible. Retrieved from https://talkiesnetwork.com/2018/03/25/using-avatar-the-last-airbender-to-explainwhy-cultural-appropriation-is-wrong-but-morally-permissible/

Hall, S. (1997). The work of representations. In S. Hall (Ed.), Representation: Cultural Representations and Signifying Practices (pp. 16-74). SAGE Publications Ltd.

Hayes-Roth, B., Doyle, P. (1998). Animate characters. Autonomous Agents and Multi-Agent Systems (1), 195-230. https://doi.org/10.1023/A:1010019818773

Hayes-Roth, B., Maldonado, H., \& Moraes, M. (n.d.). Designing for Diversity: Multi-Cultural Characters for a Multi-Cultural World. Retrieved from https://hci.stanford.edu/publications/2002/Design4Diversity/Design4Diversity.pdf

Hutcheaon, L. (2006). A theory of adaptation. New York/London: Routledge.

Hutcheon, L., \& O'flynn, S. (2013). A theory of adaptation. Routledge.

Langfitt, F. (1999). Disney magic fails "Mulan" in China; Cultures: The Americanized version of the famous folk tale is all too American for Chinese movie audiences. The Baltimore Sun. https://www.baltimoresun.com/news/bs-xpm-1999-05-03-9905030250-story.html

Lioi, I. (2009). Framework of development for schemata in computer design for animation (Master's Thesis). Retrieved from

https://etd.ohiolink.edu/apexprod/rws_etd/send_file/send?accession=osu124543262 6\&disposition=inline

Mughal, H. A. (2019). Support at Work and its Relationship with Employee Performance:

Critical Insights for Early Scholars. Annals of Contemporary Developments in

Management \& HR (ACDMHR), 1(3), 16-21.

Nieuwboer, M. E. (2019). Representation of Mexican culture in animation films for children: An analysis of Coco and The Book of Life [Master's Thesis]. https://dspace.library.uu.nl/handle/1874/383777

Perdikaki, K. (2017). Adaptation as translation: Examining film adaptation as a recontextualised act of communication [PhD]. http://epubs.surrey.ac.uk/id/eprint/812918

Perdikaki, K. (2018). Film adaptation as the interface between creative translation and cultural transformation: The case of Baz Luhrmann's 'The Great Gatsby'. The Journal of Specialised Translation, 20, 169-187.

Rall, H. (2020). Adaptation for animation. Taylor \& Francis Group: CRC Press. 
Richardson, K. (2008). Introduction: Humorous Subversions: Animation as Cultural Critique. Studies in American Humor, 17 (3), 7-10. Retrieved from http://www.jstor.org/stable/42573533

Solomon, C. (2015). Diversity can be heard and seen in animated films. LA Times. Retrieved from https://www.latimes.com/entertainment/movies/la-et-mn-animation-diversity20150215-story.html

UNESCO (n.d.). Culture for sustainable development. https://en.unesco.org/themes/culturesustainable-development

Wells, P. (2006). The fundamentals of animation. Singapore: AVA Book Production Pte. Ltd.

Wells, P. (1998). Understanding animation. New York/London: Routledge.

Ying, J. (2014). Popular Culture and Public Imaginary: Disney vs. Chinese stories of Mulan. Journal of the European Institute for Communication and Culture, 18(1). 53-74.

Yoshinaga, I. (2019). Disney's Moana, the Colonial Screenplay, and Indigenous Labor Extraction in Hollywood Fantasy Films. Narrative Culture, 6(2), 188-215. Retrieved from https://www.jstor.org/stable/10.13110/narrcult.6.2.0188 